\title{
Sobre recepções, heranças e encontros: Uma resenha de Saussure e Benveniste no Brasil, de Valdir do Nascimento Flores
}

Carolina Knack

Professora Adjunta do Instituto de Letras e Artes (ILA) da Universidade Federal do Rio Grande (FURG); E-mail: carolinaknack@furg.br.

Giovane Fernandes Oliveira

Mestrando em Estudos da Linguagem do Programa de Pós-Graduação em Letras da Universidade Federal do Rio Grande do Sul (UFRGS);

E-mail: giovane.oliveira@ufrgs.br.

\section{Resenha do livro:}

FLORES, Valdir do Nascimento. Saussure e Benveniste no Brasil: quatro aulas na École Normale Supérieure. São Paulo: Parábola Editorial, 2017.

Abarcando com o olhar esse meio século decorrido, podemos dizer que Saussure cumpriu bem o seu destino. Além da sua vida terrena, as suas ideias brilham mais longe do que ele teria podido imaginar, e esse destino póstumo se tornou como uma segunda vida, que se confunde para sempre com a nossa.

Émile Benveniste

As palavras acima são de Émile Benveniste, em texto intitulado Saussure após meio século, escrito em 1963 em homenagem ao cinquentenário da morte do linguista suíço e publicado em 1966 em Problemas de Linguística Geral I. Tais palavras denotam o respeito e a admiração de Benveniste pelo legado saussuriano, desvelando uma relação estreita entre dois dos maiores nomes da linguística do século XX.

Acerca dessa relação, já falaram muitos intérpretes renomados das obras dos dois pensadores. Normand (2009) pontua alguns discursos sobre a relação Saussure-Benveniste, como o da filiação, o da novidade, o da comparação ou 
influência, dentre outros, mas defende um discurso diferente, afirmando que Benveniste encontrou Saussure e "foi além" dele no estudo da significação, aliando às regularidades da análise semiótica as particularidades da análise semântica. Por sua vez, Dessons (2006) aborda a relação entre os linguistas focalizando dois aspectos: a) a consideração da realidade intrínseca da língua, com os princípios do signo e da sincronia, que interessam a ambos por afastarem a língua de pressupostos filosóficos ou históricos; b) a centralidade do falante, presente em Saussure na mudança da perspectiva diacrônica para a perspectiva sincrônica derivada da relação dos falantes com a língua e, em Benveniste, na realização do sistema linguístico pelo locutor que se constitui como sujeito no presente de sua fala.

Não é, contudo, de aproximações e distanciamentos entre Saussure e Benveniste que trata Valdir do Nascimento Flores em seu mais recente livro, Saussure e Benveniste no Brasil: quatro aulas na École Normale Supérieure (Parábola Editorial, 2017). Professor Titular de Linguística e Língua Portuguesa do curso de graduação em Letras da Universidade Federal do Rio Grande do Sul (UFRGS) e docente orientador do Programa de Pós-Graduação em Letras da mesma instituição, Flores tem, nessa nova obra, um interesse de ordem epistemológica: ele busca traçar uma história crítica da recepção das ideias saussurianas e benvenistianas pela linguística brasileira. Na Introdução do livro, Flores expõe a gênese de sua obra: trata-se da compilação de quatro conferências ministradas no início de 2016, na École Normale Supérieure (ENS), em Paris, nas quais o professor foi convidado a falar sobre a recepção dos pensamentos de Ferdinand de Saussure e Émile Benveniste no Brasil. O livro reproduz cada conferência dada por Flores na instituição francesa, motivo pelo qual é organizado em quatro capítulos, denominados "Aulas".

Ainda na Introdução, honrando a máxima saussuriana segundo a qual o ponto de vista cria o objeto, Flores esclarece que não busca apresentar "a" história da presença desses teóricos em contexto brasileiro, mas uma interpretação crítica e pessoal sobre tal história. $\mathrm{O}$ autor declara que, em vez de assumir uma visada cronológica ou, ainda, de reportar as interpretações acerca de Saussure e Benveniste empreendidas por precursores da linguística brasileira, optou "por fazer uma narrativa pessoal (e qual não é?)" (FLORES, 2017, p. 12). 
A aparente obviedade da pergunta denuncia a lucidez do pesquisador, que abre parênteses para testemunhar, com sua obra, o princípio mesmo que assinala: se, com Saussure e Benveniste, "[...] somos obrigados a desconfiar do alinhamento da linguística a um modo de fazer ciência que ignore o essencialmente humano, a capacidade simbólica de produzir sentido" (FLORES, 2017, p. 12), com a obra de Flores somos obrigados a desconfiar de um fazer científico que dele exclua a figura do pesquisador. Pensamos que essa posição pode ser mais bem compreendida se levarmos em conta o que explica o professor em sua primeira aula.

Na Aula 1, intitulada Recepção da linguística de Ferdinand de Saussure no Brasil, Flores afirma a necessidade de estabelecimento de um ponto de vista a partir do qual apresentar o que compreende por recepção das ideias saussurianas no Brasil. Para tanto, divide essa aula em três partes. Cabe destacar que tais divisões são cuidadosamente anunciadas ao leitor, assim como o são as transições entre os argumentos construídos pelo autor no interior de cada parte, tanto desta primeira aula quanto das demais. Esta primeira aula está organizada a propósito do aparecimento, no Brasil, de duas obras saussurianas: o Curso de Linguística Geral (CLG ou Curso) e os Escritos de Linguística Geral (Escritos). Segundo Flores, não são os textos, em si, o objeto de sua argumentação, mas o fato de seu aparecimento. E, para disso tratar, o autor inspira-se na noção de superstes do filósofo Giorgio Agamben: "Ser um superstes significa contar uma história de dentro da história" (FLORES, 2017, p. 23). É essa a condição que, devidamente explicada na primeira parte, Flores assume para interpretar a presença de Saussure em nosso país. Essa interpretação dá-se, segundo ele, après-coup, cujo tempo "é o de um presente que se volta sobre si mesmo." (FLORES, 2017, p. 23). Aqui, é Lacan quem inspira o professor.

Esclarecidos esses princípios, de caráter, sobretudo, metodológico, Flores destaca, ainda nessa primeira parte da Aula 1, que o contexto institucional e epistemológico em que se deu o aparecimento do Curso de Linguística Geral no Brasil não coincide com o que ocorreu na França. $\mathrm{O}$ autor mostra que, no Brasil, primeiramente, foi "importada" uma leitura de Saussure; portanto, Saussure foi lido "de segunda mão", haja vista que a tradução do CLG apenas se deu em 1970 - eis a discussão que também será feita na terceira parte ("O Saussure 
de ontem"), que se desenvolve a partir do questionamento acerca da existência de um paradigma disciplinar decorrente da recepção da linguística saussuriana em nosso país. Além disso, Flores (2017, p. 40) mostra que, no contexto brasileiro, a perspectiva sincrônica de abordagem da língua chegou até nós a partir de Joaquim Mattoso Camara Jr., este influenciado pela "interpretação estruturalista das ideias de Saussure operada por Jakobson", de quem Mattoso foi aluno.

No entanto, Flores adverte, na segunda parte da Aula 1, que há uma leitura atual do pensamento de Saussure no Brasil que foi possível em virtude de três acontecimentos: a tradução dos Escritos de Linguística Geral (2004), a partir da qual se voltou a ler o próprio CLG e a perceber aspectos antes não vistos; a tradução de Introdução à leitura de Saussure (2000), de Simon Bouquet, e o crescimento de relações institucionais e acadêmicas entre Brasil e França. Havendo uma nova perspectiva inaugurada por essas obras, Flores argumenta que o impacto da tradução dos Escritos no Brasil foi maior que a do CLG. Essa tese, devidamente sustentada nesta primeira aula, ancora-se na concepção de Flores (2017, p.27) acerca da palavra impacto, pressuposta na afirmação de que "[...] nada de novo se instituiu na linguística brasileira porque o CLG fora traduzido", ao contrário do que o autor acredita ter ocorrido com a tradução dos Escritos. O impacto, portanto, pode ser avaliado a partir do redimensionamento que a nova visada conferiu aos estudos linguísticos. Nesse contexto, Flores se surpreende com certa leitura que ainda se faz de Saussure: "Há, sem dúvida, quem o relacione, na atualidade, ao estruturalismo (ainda há!!!) [...]." A tripla exclamação não passa despercebida e assume valor crítico. Segundo o professor, a ausência de um olhar prospectivo em relação às potencialidades do pensamento saussuriano gera uma "[...] consequência grave: o Saussure ensinado nos cursos de graduação em Letras do Brasil ainda é, em sua maioria, um Saussure dicotômico, estruturalista e com pouco, ou nenhum, potencial de inovação." (FLORES, 2017, p.32).

O livro de Flores caminha, sem dúvida, na contramão desse discurso, pois provoca o leitor a redescobrir Saussure e a passar de um estudo retrospectivo - cuja importância não é negada por Flores, uma vez que a considera fundamental para compreender o pensamento de Saussure - para um 
prospectivo, cujos exemplos, mencionados pelo autor, são possibilidades de trabalhos desenvolvidos por Simon Bouquet e Claudine Normand. É nesse ponto que Flores (2017, p. 31) volta a problematizar a noção de recepção: “Ora, a recepção de um pensamento não implicaria avaliar as potencialidades que ele tem de dar horizontes ao campo do qual ele mesmo se origina?" Se há outro grande mérito da obra de Flores, pensamos ser o de convocar o leitor a enveredar por esses caminhos já abertos: "A história da presença das ideias de Saussure no Brasil ainda está por ser feita." (FLORES, 2017, p. 22).

$\mathrm{Na}$ Aula 2, intitulada Recepção do pensamento de Benveniste no Brasil, Flores organiza sua exposição em duas partes, uma mais cronológica e outra mais crítica. Na primeira parte, o autor situa o advento da reflexão benvenistiana no país entre as décadas de 1960 e 1990, a partir da relação entre a tradução da obra e o contexto epistemológico e institucional brasileiro de então. Destaca-se, nessa parte inicial, a tese defendida por Flores (2017, p. 53) de que "a recepção do pensamento benvenistiano no Brasil é parcial, dispersa e fragmentada"; tais parcialidade, dispersão e fragmentação seriam resultantes de uma falta de leitura do conjunto da obra, por sua vez decorrente dos longos intervalos de tempo entre as traduções brasileiras, bem como da limitação das referências a Benveniste ao campo da enunciação e da interpretação dessa temática por outros campos dos estudos da linguagem.

Acerca dessa interpretação, na segunda parte da Aula, Flores apresenta e posiciona-se criticamente em relação a leituras que Benveniste recebeu, no país, de estudiosos da análise do discurso, da linguística textual e da pragmática. Segundo o autor, "Trata-se de uma leitura parcial (os pesquisadores interessam-se apenas pela reflexão no campo da enunciação) e fragmentada (apenas alguns termos e noções são apresentados)", de modo que "a teoria é interpretada em um quadro epistemológico estranho a sua configuração original" (FLORES, 2017, p. 67). Não se pode deixar de constatar, aqui, a seriedade com que Flores encara a relação - sempre delicada e (por que não?) arriscada - do intérprete com a teoria. $\mathrm{O}$ autor conclui a Aula 2, porém, observando que, se as ideias benvenistianas não repercutiram inicialmente no Brasil em função de leituras inadequadas ou superficiais, atualmente, 
Benveniste foi redescoberto pelos linguistas brasileiros. A respeito dessa nova recepção, Flores discorre na aula seguinte.

Na Aula 3, intitulada Benveniste no Brasil - A presença de Últimas Aulas: Collège de France 1968 e 1969, o autor também divide sua explanação em duas partes. Na primeira parte, Flores ressalva que, ao falar de uma primeira recepção de Benveniste no Brasil (a abordada na aula anterior) e de uma segunda recepção (a que será explorada nesta), não pretende fixar uma leitura mais correta ou completa da obra do linguista - cuja complexidade e diversidade ele afirma justificarem recepções variadas e diferentes leituras -, mas antes assinalar que houve uma mudança de atitude dos pesquisadores brasileiros em relação à obra benvenistiana. Três indícios, conforme o autor, permitem falar em tal mudança: a) o interesse pela leitura do texto de Benveniste em si, mais do que por textos de outros autores sobre ele; b) o grande número de disciplinas em cursos de mestrado e doutorado e o consequente aumento de estudos sobre aspectos do pensamento de Benveniste não restritos ao escopo da enunciação; c) o interesse pela reflexão benvenistiana por parte de pesquisadores de outros campos, como a antropologia, a história, a filosofia, a psicanálise, a fonoaudiologia etc. Flores vê, nesses três indícios, "um elemento comum: a preocupação em ler Benveniste", o que "é suficiente para inaugurar uma segunda recepção da obra do autor no Brasil" (FLORES, 2017, p. 74, grifos do autor), sobre a qual trata na segunda parte da Aula.

Nessa parte, o autor apresenta o que entende por segunda recepção de Benveniste no Brasil a partir de três eixos didaticamente organizados em um quadro, que ele pontua não consistirem em uma classificação rígida dos estudos enunciativos benvenistianos no país. No primeiro eixo, encontram-se trabalhos que colocam a enunciação no centro da reflexão e produzem uma linguística enunciativa stricto sensu, inspirada nos aspectos teórico-metodológicos delineados no famoso texto de Benveniste de 1970, O aparelho formal da enunciação. Acerca desse eixo, Flores (2017, p. 79) faz a interessante ressalva de que "a enunciação recobre estudos específicos das formas linguísticas de dada língua, mas não pode ser reduzida a isso, uma vez que ela tem, também, uma dimensão global que atravessa toda a linguagem". Já no segundo eixo, predominam estudos que se centram na 
enunciação, mas a articulam com o conjunto da teoria da linguagem de Benveniste, produzindo uma abertura ao diálogo com as ciências humanas em geral. De acordo com Flores, tais estudos distinguem-se por enfatizarem a relação entre linguagem e cultura e, por conseguinte, o viés antropológico do pensamento benvenistiano; a conclusão do autor a respeito desse eixo é instigante: "o potencial teórico-metodológico da teoria de Benveniste, que ele próprio não teve a oportunidade de avaliar, está longe de se esgotar" (FLORES, 2017, p. 16). No terceiro eixo, por sua vez, destacam-se pesquisas intratéoricas, de caráter hermenêutico, que buscam esclarecer termos, noções e conceitos da teoria da linguagem de Benveniste, a qual abrange a teoria da enunciação, mas não se limita a ela. Tal eixo é vinculado pelo autor às Últimas Aulas, cuja tradução brasileira foi publicada apenas dois anos após a publicação francesa, o que confirma o interesse maior por Benveniste hoje em dia no Brasil. Embora as projeções de Flores sobre os horizontes que se abrem para os estudiosos de Benveniste entusiasmem, ao final da Aula 3, o título a ela conferido - Benveniste no Brasil - A presença de Últimas Aulas: Collège de France 1968 e 1969 antecipa um protagonismo que tal obra receberá apenas na aula seguinte, uma vez que esta se centrou nos três eixos brasileiros dos estudos benvenistianos, muito bem caracterizados pelo autor e que organizam sua exposição neste capítulo do livro.

O tempo de renovação de leitura assinalado por Flores na Aula 1 em relação a Saussure é posto em pauta na Aula 4 em relação a Benveniste. A partir da segunda recepção discutida na aula anterior, Flores destaca que as ideias de Benveniste estão sendo redimensionadas e o alcance de seu pensamento, alargado. Nesse contexto, não poderíamos deixar de dizer que o próprio Flores tem contribuído para essa "nova realidade", da qual seu livro dá testemunho ao lado de outras publicações suas que põem em evidência uma teoria da linguagem sustentada na tríade homem, linguagem e cultura. Como alertou o professor, as Últimas Aulas têm colaborado substancialmente para isso, motivo pelo qual reservou uma aula para desenvolver duas possibilidades de interpretação em relação a esse manuscrito que, segundo compreende, "aborda as relações dos diferentes sistemas semiológicos e a escrita", o que, para Flores, "é um tema não circunscrito à linguística" (FLORES, 2017, p. 92). A primeira é a de que a obra coloca 
em relevo aspectos que foram problematizados "en passant" nos textos de que tínhamos conhecimento, especialmente, segundo o autor, O aparelho formal da enunciação e Semiologia da língua, artigos integrantes de Problemas de Linguística Geral II (BENVENISTE, 2006); e a segunda é a de que a obra, vista de modo articulado a outros escritos do linguista, apresenta o esboço das "grandes linhas de uma nova disciplina, a 'semiologia da língua'” (FLORES, 2017, p. 93).

Assim, a aula em questão divide-se em duas partes, cada qual dedicada a construir um "exercício de interpretação" para as duas questões formuladas anteriormente. Dentre os pertinentes apontamentos de Flores, destacamos aquele que serve de advertência ao leitor de Benveniste: a escrita de que fala Benveniste em O aparelho formal da enunciação ao mencionar a enunciação escrita não é a mesma de que fala nas Últimas Aulas. Nesta, de acordo com o entendimento de Flores (2017, p. 103), é a noção de interpretância da língua que está em pauta e "A escrita seria a prova de que a língua interpreta a si própria. A escrita é a evidência da autossemiotização da língua." Muito mais poderia ser dito, aqui, a respeito dessa importante colocação. No entanto, o leitor que for à Aula 4 em busca de prontas respostas pode se surpreender, pois nela encontrará um movimento prospectivo que o convoca a construir possibilidades de interpretação. A título de exemplo, citamos a reflexão de Flores sobre a escrita no contexto de $O$ aparelho formal da enunciação: a escrita, citada no parágrafo final do artigo referido, "é uma forma complexa que mereceria um estudo específico?" (FLORES, 2017, p. 98). Eis a pergunta em suspenso.

Dessa maneira, assim como Flores, ao longo de sua própria obra, aborda a recepção de Saussure e Benveniste em movimentos de retrospecção e prospecção, pensamos que seu livro também pode ser recebido nesses termos, resguardadas as devidas proporções: ao mesmo tempo em que a obra de Flores testemunha uma retrospectiva acerca das linguísticas de Saussure e Benveniste e seus encontros, ela lança em prospecção tarefas para o linguista que se interessa pelo pensamento desses mestres. Muito há para ser feito, e Flores apresenta, com perspicácia, vários caminhos. Nesse ponto, acreditamos que passamos da ideia de recepção para a de herança, como destaca Flores a propósito do belo trabalho de Claudine Normand. Deslocando tal ideia para o contexto da própria obra de Flores, 
pensamos ser por meio de nossa leitura do saber inacabado que o autor tão criteriosamente demonstra em seu texto, o qual se impõe a nós como herança, que fazemos nossas escolhas e escolhemos preservar vivas as ideias desse pesquisador, e, por isso, nós, jovens linguistas, alunos e professores, sempre em formação, as reinterpretaremos nos contextos de nossas pesquisas. Parafraseando as belas palavras de Benveniste acerca de Saussure, que servem de epígrafe a esta resenha, diríamos que as ideias de Flores brilham mais longe do que ele talvez possa imaginar e que sua leitura das obras saussuriana e benvenistiana se tornou como uma segunda vida, que se confunde para sempre com a nossa.

É conhecida a afirmação de Barthes, em $O$ rumor da língua (2004), em relação aos atributos da obra de Benveniste. Não seria exagero estendê-la ao recente livro de Flores: Há uma beleza, uma experiência do intelecto, que dá à obra de certos cientistas essa espécie de clareza inesgotável de que também são feitas as grandes obras literárias. Tudo é claro no livro de Valdir do Nascimento Flores, tudo nele pode imediatamente ser reconhecido como verdade; $e$, no entanto, tudo também nele não faz mais do que começar.

\section{REFERÊNCIAS}

BARTHES, R. O rumor da língua. 2.ed. São Paulo: Martins Fontes, 2004.

BENVENISTE, É. Saussure após meio século (1963). In: Problemas de Linguística Geral I. 2.ed. Campinas, SP: Pontes Editores, 2005.

DESSONS, G. Le fil d'Ariane de la sémantique. In: Émile Benveniste, l'invention du discours. Paris: Éditions in Press, 2006.

FLORES, V. N. Saussure e Benveniste no Brasil: quatro aulas na École Normale Supérieure. São Paulo: Parábola Editorial, 2017.

NORMAND, C. Saussure-Benveniste. In: Convite à Linguística. São Paulo: Contexto, 2009. 